\title{
A Market-Based Virtual Power Plant
}

\section{You, Shi; Træholt, Chresten; Poulsen, Bjarne}

\section{Published in:}

International Conference on Clean Electrical Power

Link to article, DOI:

10.1109/ICCEP.2009.5212012

Publication date:

2009

\section{Document Version}

Publisher's PDF, also known as Version of record

Link back to DTU Orbit

Citation (APA):

You, S., Træholt, C., \& Poulsen, B. (2009). A Market-Based Virtual Power Plant. In International Conference on Clean Electrical Power (pp. 460-465). IEEE. https://doi.org/10.1109/ICCEP.2009.5212012

\section{General rights}

Copyright and moral rights for the publications made accessible in the public portal are retained by the authors and/or other copyright owners and it is a condition of accessing publications that users recognise and abide by the legal requirements associated with these rights.

- Users may download and print one copy of any publication from the public portal for the purpose of private study or research.

- You may not further distribute the material or use it for any profit-making activity or commercial gain

- You may freely distribute the URL identifying the publication in the public portal

If you believe that this document breaches copyright please contact us providing details, and we will remove access to the work immediately and investigate your claim 


\title{
A Market-Based Virtual Power Plant
}

\author{
Shi You Student Member IEEE*, Chresten Træholt*, Bjarne Poulsen** \\ * Technical University of Denmark, Department of Electrical Engineering, Elektrovej 325, 2800 Kgs. Lyngby, (Denmark) \\ ** Technical University of Denmark, Department of Informatics and Mathematical Modeling, \\ Richard Petersens Plads 322, 2800 Kgs. Lyngby, (Denmark)
}

\begin{abstract}
The fast growing penetration of Distributed Energy Resources (DER) and the continuing trend towards a more liberalized electricity market requires more efficient energy management strategies to handle both emerging technical and economic issues. In this paper, a market-based Virtual Power Plant (MBVPP) model is proposed which provides individual DER units the accesses to current electricity markets. General bidding scenario and price signal scenario as two optional operation scenarios are operated by one MBVPP. In the end, a use case of a MBVPP with micro Combined Heat and Power ( $\mu$ CHP) systems demonstrates the potential benefits and operation scenarios of the MBVPP model.
\end{abstract}

Index Terms-Distributed Energy Resources, Electricity market, market-based Virtual Power Plant

\section{INTRODUCTION}

The penetration of Distributed Energy Resources (DER) is growing fast all over the world, which is mainly attributed to the requirement of a sustainable energy system with less environmental pollution, more diversified energy resources and improved energy efficiency [1]. In the meanwhile, the ongoing process of liberalization of the electricity market, i.e. the transition from the former monopolistic to competitive market structures, also attracts more and more attention [2]. In the context of these two tendencies, running a great number of DER units under market conditions is inevitable, which yet poses new challenges that have to be addressed.

- Market participation: Regarded as small, modular power generation, storage technologies and controllable loads [3], DER is generally prohibited from entering the current electricity market [4].

- Intermittent nature: As many DER technologies like photovoltaic systems and wind turbines are weatherdependent, their stochastic output is therefore considered non-dispatchable which not only limits their contribution to grid operation, but also causes economic penalties associated with unexpected unbalances.

- Stand alone: Many DER units are working alone due to their different ownerships. Cooperation and communication often lack between neighboring DER units, thus the capability of DER is confined to satisfy the local needs rather than to complement the entire grid.

One way to address these issues is to aggregate a number of DER units in a so-called Virtual Power Plant (VPP). In this construction, the group of DER units will have the same visibility, controllability and market functionality as the conventional transmission-connected

This work was supported by the Danish PSO contract 7572 . power plants. As aggregation can be guided by functional needs, geographical locations, the nature of generation technologies, points of injection or other kinds of commonalities, designs and implementations of VPP have rarely reached a consensus[5]-[10]. However, VPP can be divided into three basic categories which differ from each other in control architectures and associated information directions.

- $\quad$ Centralized Controlled VPP (CCVPP): requires the VPP has the complete knowledge of involved DER units and defines every operating set point to meet the varying requirements of the local power system [5]-[7].It has a high potential for reaching optimal operation, but is often case specific which results in limited scalability and compatibility.

- $\quad$ Decentralized Controlled VPP (DCVPP): refers to a collection of distributed local controllers which constitute an overall hierarchical architecture [8]. The weakness of CCVPP can be conquered by the modularity and intelligence of local controllers. However, a central controller is still required to sit on top of a DCVPP in order to ensure the system security and an overall economic operation.

- $\quad$ Fully Decentralized Controlled VPP (FDCVPP): is an extension of DCVPP, wherein central controllers are replaced by information exchange agents which only provide valuable services e.g. market price signal, weather forecasting and data logging etc. to FDCVPP participants [9]-[10]. It has a relatively higher scalability and openness than the other architectures as it relies on plug and play ability. In the event of actualizing the internet model of the future power system [11] pictured by the EU research commission, a successful FDCVPP will be taken as the foundation towards operating a fully distributed power system in which every node in the electrical network is awake, responsive, eco-sensitive and price smart.

In this paper, a market-based VPP (MBVPP) model, as one kind of FDCVPP, is proposed. It offers the generic path to small DER units to trade in today's electricity market and takes the advantages of market nature in efficient resources allocation. In section II, a brief review is given to the current electricity market structure, followed by detailed illustrations on design of the MBVPP architecture and associated operation scenarios. In section III, a case study is performed to demonstrate the operation scenarios mentioned in the previous section. Conclusion and directions for future work are offered in Section IV.

\section{DESIGN OF A MBVPP}

The objective of MBVPP is to offer a generic path for 
all kinds of DER units to get access to today's electricity market; therefore challenges faced by DER can be addressed by the self-regulating capability of the electricity market. In order to achieve this goal, the design of a MBVPP has to be based on the study of today's electricity market principle and to ensure a seamless linkage between the internal MBVPP organized market and the external global electricity market, e.g. Nordpool [12].

\section{A. Time Frame for Today's Electricity market}

A general summary of the overall time frame for trading electricity and ancillary services is given in Fig 1 . Long term forward contracts take place from months or years before a trade is executed. Day-ahead market provides market participants with the option to play in short term forward market. Sometimes, an intra-day market kicks in and provides continuous power trading up to one hour prior to delivery. Balancing market, also known as regulating market, which extends from realtime to day ahead, is part of the overall energy market that provides balancing power/energy to electric power system operation at a short term notice. Furthermore, market for ancillary services covers a time frame from long term to real time and interacts with all aforementioned energy markets. These services are the processes and actions associated with power system operation, which are provided by market participants and generally managed by the transmission system operators (TSOs). Similar services are procured by distribution system operators (DSOs) for the purpose of maintaining the power system security at the distribution level.

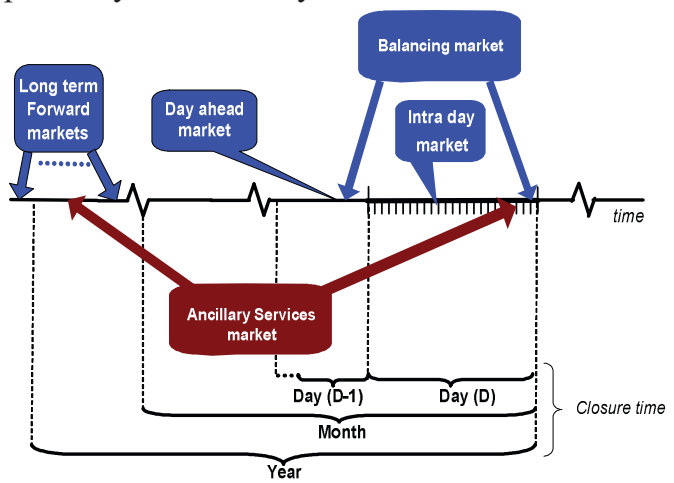

Fig. 1. Time frame for trading electricity \& ancillary services

\section{B. Architecture of the MBVPP}

As given in Fig 2, a MBVPP provides a platform through which every DER gains a seat in any of the aforementioned electricity markets. In principle, most of the DER units give priority to serving their individual demand; therefore only excessive generation will be sold back to the grid. Electrical power flow goes through the point of common coupling (PCC) from the MBVPP to meet either local demand or demand in other areas across the distribution and transmission system. Generally, a MBVPP can perform activities in at least three distinct fields:

- $\quad$ Electricity Market: A MBVPP is able to trade with any other market player e.g. brokers, traders, DSOs,
TSOs and even other MBVPPs in terms of bilateral contracts or power exchange. All the arranged trades have to be checked by TSOs or DSOs to ensure the power system security at different levels.

- Internal Market: A MBVPP acts as a market operator as well as a service operator. It offers different market scenarios like bidding scenario and price signal scenario to meet the different customers' requirements. Bilateral trading can also take place between individual DER units if desired as depicted in Fig 2. As the point of common coupling (PCC) for MBVPP is within the distribution network, DSOs have to be responsible for the security issues within the MBVPP.

- Other Business Fields: If the number of participants increases to a certain level, it may be possible for the MBVPP to intervene in other business fields such as fuel markets and carbon markets or to become a legal entity. Each participant may thus achieve further benefits.

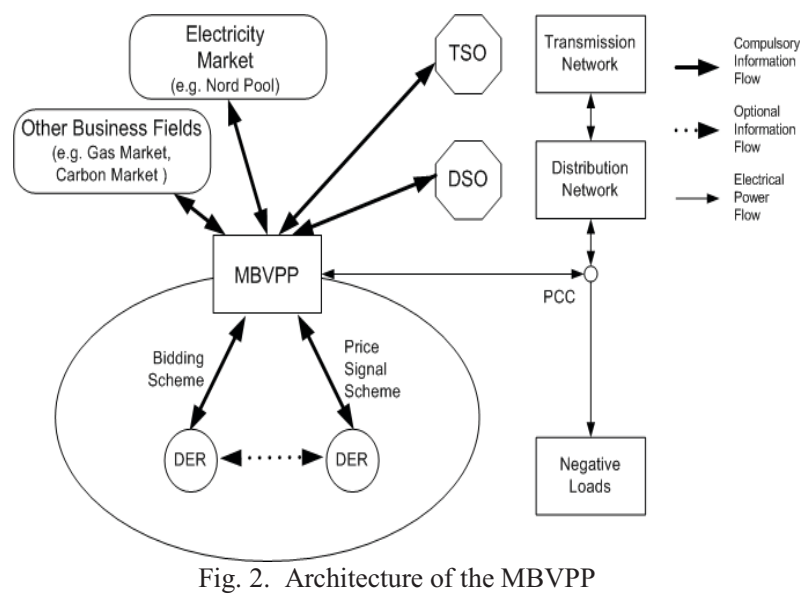

\section{Internal Market Scenarios}

In an attempt to make all DER units operate costeffectively, a MBVPP offers two optional market scenarios in its internal market: general bidding scenario and price signal scenario. Both scenarios are flexible in the time frame of trading, therefore seamless coordination between the internal market and the external market is established. Communication is presumably implemented via the internet under a flawless operation.

\section{1) Scenario 1: General Bidding}

DER units who select the general bidding scenario will be paid at the electricity market price if their bids are accepted; therefore the profit is closely related with their own intelligence. An example of applying the internal market scenario to cooperating with the Nord Pool Spot [13], a typical day-ahead market for power exchange, is given in Table I. During this period, the MBVPP operator is only responsible for information exchange with different partners and bid aggregation while each DER has to develop its own optimal operation schedule for the next day based on the MBVPP forecasted information. In terms of fitting into other wholesale market time frames, like hour ahead or 15 minutes ahead, similar routines can be developed. 
TABLE I

COOPERATION BETWEEN THE MBVPP'S INTERNAL DAY-AHEAD MARKET AND NORD POOL SPOT

\begin{tabular}{|c|l|}
\hline Time & \multicolumn{1}{c|}{ Routine } \\
\hline $8: 00-10: 00$ & $\begin{array}{l}\text { Price forecasts for tomorrow's wholesale market is } \\
\text { performed by the MBVPP }\end{array}$ \\
\hline $10: 00-10: 30$ & $\begin{array}{l}\text { Bids are submitted by DER owners to the MBVPP's } \\
\text { internal day-ahead market }\end{array}$ \\
\hline $10: 30-11: 30$ & MBVPP aggregates the bids \\
\hline $11: 30-12: 00$ & $\begin{array}{l}\text { MBVPP submits the aggregated bids to Nord Pool } \\
\text { Spot }\end{array}$ \\
\hline$(13: 00-14: 00)$ & $\begin{array}{l}\text { Nord Pool Spot clears the market and informs the } \\
\text { MBVPP }\end{array}$ \\
\hline$(14: 00-19: 00)$ & MBVPP makes a final aggregated production plan \\
\hline$(15: 00-19: 00)$ & Final production schedule is submitted to the TSO \\
\hline$(16: 00-19: 00)$ & $\begin{array}{l}\text { Final production schedule is determined by the TSO } \\
\text { and sent back to the MBVPP }\end{array}$ \\
\hline $19: 00-20: 00$ & $\begin{array}{l}\text { Final production schedule is sent to DSOs for } \\
\text { security check }\end{array}$ \\
\hline $20: 00-21: 00$ & $\begin{array}{l}\text { Final production schedule are approved/revised by } \\
\text { DSOs and sent back to the MBVPP }\end{array}$ \\
\hline $21: 00-22: 00$ & $\begin{array}{l}\text { Each DER unit receives its final production schedule } \\
\text { for tomorrow from the MBVPP }\end{array}$ \\
\hline Note: Time periods in brackets are realistic with Nord Pool Spot [13]
\end{tabular}

\section{2) Scenario 2: Price Signal Control}

The price signal market scenario allows DER owners to response to a series of price signals published by the MBVPP operator for their generation planning or real time operation. Certain degree of indirect control over the DER units is thus obtained by MBVPP operator through varying price signals; however the intelligence level of MBVPP operator has to be highly raised compared to the one required in the bidding scenario.

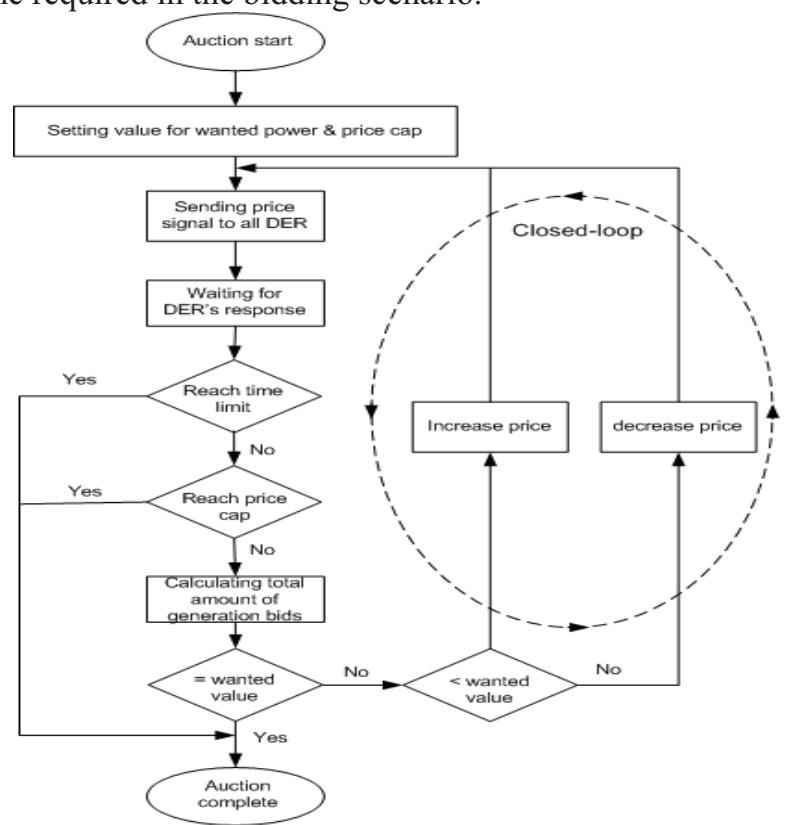

Fig. 3. Price signal market scenario of the MBVPP

As illustrated in Fig. 3, at the beginning of each market round, the MBVPP has to design a package which includes the target value for the volume of wanted power production during a specific time period as well as a price cap. The package can be quoted from either a bilateral contract signed with other market players or part of MBVPP's bidding curve for external market trading which is estimated by MBVPP operator. Generally, the price cap has to be set at a reasonable level in order to guarantee the profit of MBVPP developer. After sending out the first price signal to the DER owners, MBVPP operator has to wait for the responses. If the accumulated power from the feedback is lower than the wanted volume, the buy price will be raised to attract more willingness of DER units to sell their excessive generation. Vice versa, over-positive feedbacks will result in a lower price signal to cut down the overall volume. This closed-loop auction continues till the target value is reached. However, several key factors in this process have to be properly designed to ensure the flawless operation.

a. Number of participants: An auction with few participants can hardly be successful every time. Therefore only a large number of participants with diversified generation portfolios are the basis for implementing the price signal scenario.

b. Time period for each auction round: Basically, the time period for each auction can be very flexible and is only limited by communication barriers. However, if the time period is very short, for instance 1 minute, many DER units may not be able to respond in time. In case of a long period like 30 minutes, the auction may be closed much earlier and leave a time blank. Therefore, investigations over hardware limits and simulations on DER units' behaviors under different auction time periods have to be further exploited to ensure the acute cooperation.

c. Wanted volume: The wanted volume has to be lower than the overall generation capacity of MBVPP. In order to guarantee this, the MBVPP can either estimate its capacity based on the accumulated experience from learning period or make each DER unit report their available capacity before auction starts.

d. Starting price and price change: Certain range has to be reserved between starting price and price cap. Price change $\Delta p$ between each auction step has to be effective to save communication resources. Therefore, in order to develop a pricing scheme that fulfills these requirements, a comprehensive investigation on DER units' behaviors over different price signals has to be carried out

Even though the listed factors are well designed, emergency cases, like committed units suddenly turn offline, may still come along. Therefore, having local reserves and close relationships with neighboring energy resources can further enhance the system robustness. In addition, starting another shorter term auction round with emergency price could be another resort.

\section{3) General Bidding vs. Price Signal Control}

With both scenarios, MBVPP is able to provide an open platform to all kinds of DER to get access to the energy market without intervening in the decision making process of DER owners. Further, both scenarios can be applied to regulate either forward markets or an almost real time markets.

General bidding scenario as a conventional market scenario which lets market participants bid at the prices 
with their preferences. This requires high intelligence level for each DER owner, as bidding at a higher price may result in losing the opportunity of selling. Therefore, every owner has to bid at the marginal price of his system in order to pursue extra profit. However, this scenario may frustrate some DER owners if they fail to sell their excessive generation capacity continuously.

As for price signal scenario, DER units can respond to their preferred price levels. Uncertainties associated with the DER behaviors under variable price signals may result in unsuccessful auctions. In this occasion, an intensive pre-study on DER behaviors under variable price signals are necessary to enhance the market robustness under this scenario. Nevertheless, at the early stage of implementing MBVPP, this scenario may be more welcome by the DER owners since the right of decision is to some extent back to them.

From a MBVPP operator's point of view, a general bidding scenario is more reliable than a price signal scenario. A MBVPP running a general bidding scenario can live on the brokerage fees it charged from every participants and leave the risk to the DER owners. On the opposite, a MBVPP running price signal scenario has to bid in the external market based on its estimated capacity and price. As this act is prior to knowing how each DER owner will respond to the MBVPP published price signal, more risk is allocated to the MBVPP operator.

It's possible for a MBVPP to run on either of the two market scenarios independently while another possibility could be running both of them sequentially as they both expose pros and cons. Making general bidding organized internal market compatible with the external day-ahead market or hour-ahead market while making price signal controlled internal market compatible with the real time market may offer a user-friendly market to MBVPP participants, which can further provide experiences for the later internal market designs.

\section{CASE STUDY}

In this section, general bidding scenario and price signal scenario are applied to a local MBVPP's dayahead electricity trading and real time trading respectively. Objectives of the case study are to:

- $\quad$ Illustrate the MBVPP concept with a detailed simulated physical system

- Demonstrate the MBVPP internal market scenarios by numeric examples

- $\quad$ Provide the DER units, such as $\mu$ CHP system, with basic understanding of how to play in the MBVPP's internal market

As given in Fig. 4, the simulated MBVPP system is an expansion of the single $\mu \mathrm{CHP}$ system described in [14], while same symbols are used to describe the system's characteristic. Such system comprises 4 households with different daily load profiles of electricity and thermal consumption. Every household is assumed to be equipped with an identical $\mu \mathrm{CHP}$ system, all of which are connected to a $400 \mathrm{~V}$ electric feeder. Utility companies are still involved to provide electricity to each household at a fixed price level of $0.115 € / \mathrm{kWh}$. Meanwhile, the natural gas is supplied by fuel suppliers at $0.048 € / \mathrm{kWh}$ which is also assumed to be fixed in the simulation. The MBVPP therefore only buys the excessive electricity from each household after an economic optimization of each $\mu$ CHP system is carried out by each household. The model for $\mu \mathrm{CHP}$ system with optimized operation under varying electricity buyback price is also quoted from [14] with same assumptions concerning the operation of every single system, while technical parameters for every $\mu$ CHP system are given in Table II. The simulation is done with GAMS [15].

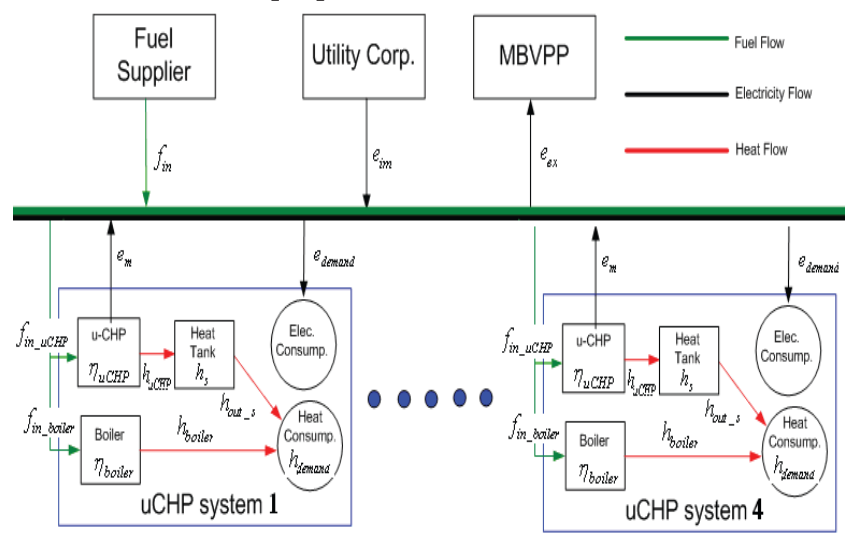

Fig. 4. Physical layout of a MBVPP

TABLE II

LIST OF VALUES FOR PARAMETERS UTILIZED IN CASE STUDY

\begin{tabular}{|c|c|}
\hline Technical Assumptions & Elaboration \\
\hline$f_{\max \text { boiler }}=30 \mathrm{~kW}$ & Auxiliary boiler \\
\hline$f_{\text {max }_{-} u C H P}=24 \mathrm{~kW}$ & $\begin{array}{l}\mu \mathrm{CHP} \text { unit with internal combustion } \\
\text { engine driven by natural gas }\end{array}$ \\
\hline$h_{s_{-} \max }=28 \mathrm{kWh}$ & $\begin{array}{l}\text { Heat tank is in size of } 500 \text { liters with } \\
\text { temperature range } 20^{\circ} \mathrm{C}-70^{\circ} \mathrm{C}\end{array}$ \\
\hline$\eta_{\text {boiler }}\left(t_{i}\right)=85.5 \%$ & \multirow{3}{*}{$\begin{array}{l}\text { Assumed to be fixed over the year (The } \\
\text { peak efficiency of modern } \mu \text { CHP unit is } \\
\text { around } 90 \% \text {; however } 80 \% \text { is used here } \\
\text { since operational conditions with lower } \\
\text { efficiency such as start up, shut down and } \\
\text { partial load are not taken into account in } \\
\text { the simulation) }\end{array}$} \\
\hline$\eta_{u C H P} \quad\left(t_{i}\right)=80 \%$ & \\
\hline$\alpha\left(t_{i}\right)=2$ & \\
\hline
\end{tabular}

\section{A. General Bidding Scenario}

The general bidding scenario, in this case, is applied to a day-ahead operation scheme. The forecasted load profiles concerning both electrical consumption and thermal consumption of each household for tomorrow are given in Fig. 4, while the spot market price is also predicted by MBVPP given in Fig. 5 .

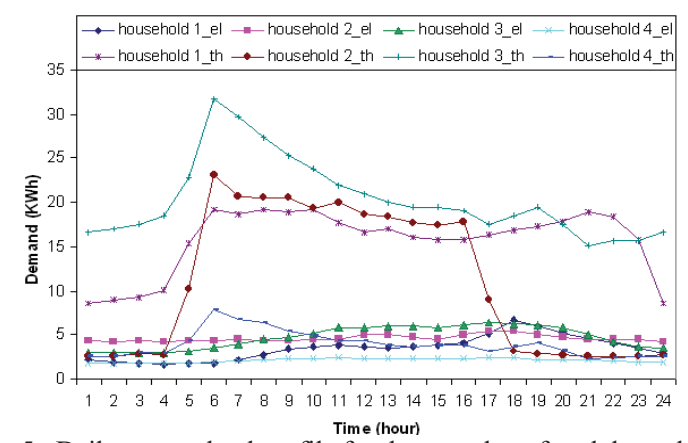

Fig. 5. Daily energy load profile for the next day of each household 


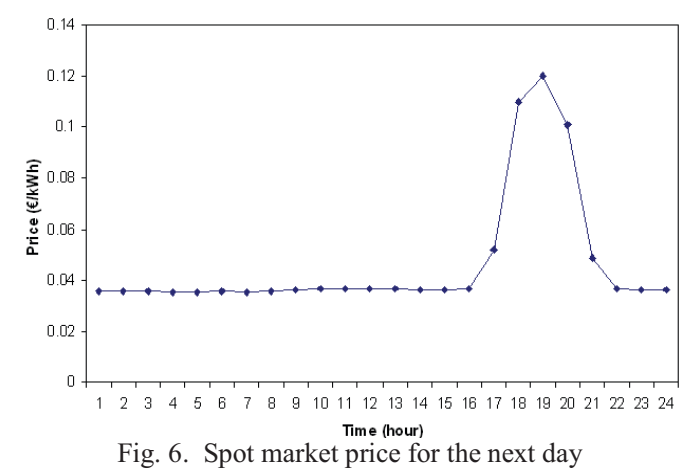

Based on the given information, each $\mu \mathrm{CHP}$ system is therefore able to make a cost-minimized generation schedule for tomorrow and bid for their excessive generation at their marginal costs when the trading is conceived profitable. Utilizing the method given in [14], the bidding blocks for each household at every single hour are derived and given in Table III. According to the predicted price curve, at most hours the householders are not willing to inject power back to the grid except for hour 18-20, when there's a price peak coming along. As long as the bids are received by the MBVPP operator, aggregation is carried out to get the overall biding blocks for each hour, as given in Table IV, which is later submitted to the external spot market.

TABLE III

BIDDING BLOCKS OF EACH HOUSEHOLD FOR THE NEXT DAY

\begin{tabular}{|c|c|c|c|c|c|c|c|c|}
\hline \multirow{2}{*}{ Hour } & \multicolumn{2}{|c|}{ Household 1 } & \multicolumn{2}{c|}{ Household 2 } & \multicolumn{2}{c|}{ Household 3 } & \multicolumn{2}{c|}{ Household 4 } \\
\cline { 2 - 9 } & $\begin{array}{c}\text { Amount } \\
(\mathrm{kWh})\end{array}$ & $\begin{array}{c}\text { Price } \\
(€ / \mathrm{KWH})\end{array}$ & $\begin{array}{c}\text { Amount } \\
(\mathrm{kWh})\end{array}$ & $\begin{array}{c}\text { Price } \\
(€ / \mathrm{KWH})\end{array}$ & $\begin{array}{c}\text { Amount } \\
(\mathrm{kWh})\end{array}$ & $\begin{array}{c}\text { Price } \\
(€ / \mathrm{KWH})\end{array}$ & $\begin{array}{c}\text { Amount } \\
(\mathrm{kWh})\end{array}$ & $\begin{array}{c}\text { Price } \\
(€ / \mathrm{KWH})\end{array}$ \\
\hline $1-17$ & - & - & - & - & - & - & - & - \\
\hline 18 & - & - & - & - & 0.1895 & 0.0677 & - & - \\
\hline 19 & 0.48 & 0.0677 & 1.4142 & 0.115 & 0.2894 & 0.0677 & 4.18 & 0.115 \\
\hline 20 & 1.296 & 0.0677 & - & - & 0.6082 & 0.0677 & - & - \\
\hline $21-24$ & - & - & - & - & - & - & - & - \\
\hline
\end{tabular}

TABLE IV

AGGREGATED BIDDING BLOCKS OF MBVPP

\begin{tabular}{|c|c|c|}
\hline \multirow{2}{*}{ Hour } & \multicolumn{2}{|c|}{ MBVPP } \\
\cline { 2 - 3 } & Amount $(\mathrm{kWh})$ & Price $(€ / \mathrm{KWH})$ \\
\hline $1-17$ & - & - \\
\hline 18 & 0.1895 & 0.0677 \\
\hline \multirow{2}{*}{19} & 0.7694 & 0.0677 \\
\cline { 2 - 3 } & 5.5942 & 0.115 \\
\hline 20 & 1.9042 & 0.0677 \\
\hline $21-24$ & - & - \\
\hline
\end{tabular}

\section{B. Price Signal Control Scenario}

The MBVPP applied with the price signal control scenario is on the assumption that it has to deliver $0.8 \mathrm{kWh}( \pm 1 \%)$ over 5 minutes from $10 \mathrm{am}$. Thus, at 9:55am, the MBVPP operator sets the price cap at $1 € / \mathrm{kWh}$ and requests the householders to report their available capacities in the wanted time period. Meanwhile, each $\mu$ CHP system develops a price function associated with its electrical production. For simplicity, this function is further assumed to be a linear function of available electrical capacity as in (1), and the overall parameter settings are randomly selected in this case as in Table VI, with exception of the values for parameter $a$ which are calculated to reflect the cost for generating one unit of electricity under two conditions depending on the accompanied heat production being useful or wasteful [16]. In practice, more concrete price functions regarding different technologies can be developed. Price change $\Delta p$ between each round of negotiation is also randomly selected by the MBVPP operator.

$\mathrm{P}_{\mathrm{el}}=a \mathrm{X}+b$

Where $\mathrm{P}_{\mathrm{el}}$ is the price, at which the householder wants to sell his excessive electrical capacity $(€ / \mathrm{kWh}) ; \mathrm{X}$ is the available electrical capacity of $\mu \mathrm{CHP}$ system for the required period $(\mathrm{kWh}) ; a$ and $\mathrm{b}$ are constants that reflect the market value associated with electrical generation $(€)$ and the householder's add-on value $(€ / \mathrm{kWh})$ respectively.

TABLE VI

PARAMETER SETTINGS FOR EACH HOUSEHOLD

\begin{tabular}{|c|c|c|}
\hline & Price Function & $\begin{array}{c}\text { Available Electrical Capacity } \\
(\mathrm{kWh})\end{array}$ \\
\hline Household 1 & $\mathrm{P}_{\mathrm{EL} 1}=0.18 \mathrm{X}_{1}+0.05$ & $0 \leq \mathrm{X}_{1} \leq 0.5$ \\
\hline Household 2 & $\mathrm{P}_{\mathrm{EL} 2}=0.05 \mathrm{X}_{2}+0.09$ & $0 \leq \mathrm{X}_{2} \leq 0.2$ \\
\hline Household 3 & $\mathrm{P}_{\mathrm{EL} 3}=0.05 \mathrm{X}_{3}+0.02$ & $0 \leq \mathrm{X}_{3} \leq 0.3$ \\
\hline Household 4 & $\mathrm{P}_{\mathrm{EL} 4}=0.18 \mathrm{X}_{4}+0.07$ & $0 \leq \mathrm{X}_{4} \leq 0.4$ \\
\hline
\end{tabular}

The simulated result is illustrated in Fig. 6, wherein it takes 6 rounds to come on to the final agreement. The solid line with cross on it indicates the price change during the negotiation, while the bars represent the replies of each householder following the price change. Final agreement is reached at price $0.0955 € / \mathrm{kWh}$, while the total obtained energy is $0.805 \mathrm{kWh}$.

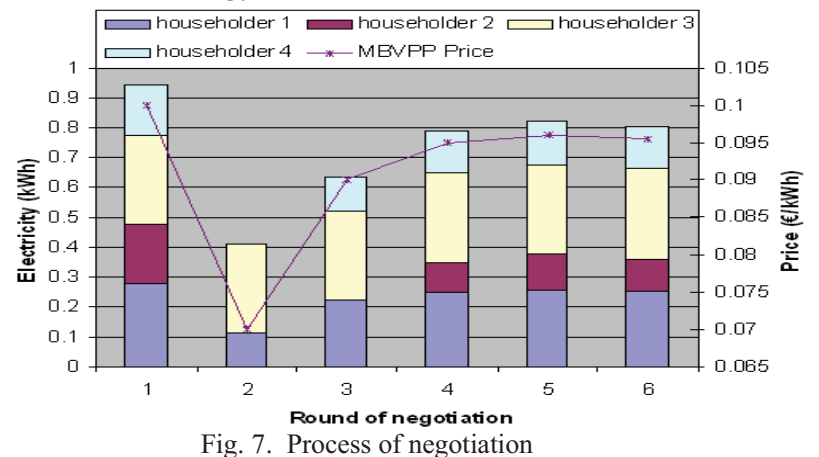

As the two scenarios are applied to different cases, total system cost associated with each scenario is not calculated and compared in this case study. However, when both scenarios are applied to a unique time frame with the same electrical demand in the simulated system, same system costs can be envisioned if $\Delta p$ is assumed to be infinitely small. In other words, the two scenarios have the same effectiveness in regulating a non-gaming market.

\section{CONCLUSIONS}

In this paper, a model for an enabling concept MBVPP is proposed to integrate DER to the current electricity market as well as the electrical grid via its internal market. Economic operation of and extra contributions to the electrical grid made by every DER unit are therefore achieved, thanks to the nature of the market. In addition to providing seamless connections between the internal 
market and the external market, a general bidding scenario and a price signal control scenario, being two flexible alternatives, are explained, compared and utilized to regulate the internal market of MBVPP. A case study of a MBVPP comprising four $\mu \mathrm{CHP}$ systems is carried out to demonstrate both market scenarios.

The work presented in this paper is part of the work in developing a generic VPP. Further exploration of related topics, such as developing an efficient pricing scheme used in the price control scenario, investigating diversified DER generation portfolios, testing the internal market efficiency and developing emergency operation schemes, is necessary. Finally, analysis is recommended to be done to reveal the possible impacts to current electricity market when a large number of MBVPPs are introduced.

\section{REFERENCES}

[1] ENIRDGnet: Concepts and opportunities of Distributed Gneration: The Driving European Forces and Trend., ENIRDGnet Project deliverable D3, 2003

[2] Junichi Ogasawara: Current status and Evaluation of Electricity market liberalization in Japan, USA and Europe. IEE $391^{\text {st }}$ regular research session, May 2005.

[3] Friedman, N. R.: Distributed Energy Resources Interconnection Systems: Technology Review and Research Needs, National Renewable Energy Laboratory Report No. NREL/SR-560-32459, September 2002.

[4] Ropenus, S.; Skytte, K.: Regulatory Review and Barriers for the Electricity Supply System for Distributed Generation in the EU-15, International Journal of Distributed Energy Resources, Vol. 3, 2007, pp. 243-257,

[5] European Virtual Fuel Cell Power Plant Management Summary Report, 2005

[6] Caldon, R.; Rossi A.; Turri, R.: Optimal Control of a Distribution System with a Virtual Power Plant. Bulk Bulk Power System Dynamics and Control-VI, Italy, Aug. 2004

[7] Bignucolo, F.; Caldon, R.; Prandoni, V.: The Voltage Control on MV Distribution Networks with Aggregated DG Units (VPP), Proceedings of the $41^{\text {st }}$ International Volume 1, Sep 2006, pp. 187-192

[8] Wu, F.F.; Moslehi, K.; Bose, A.: Power System Control Centers: Past, Present, and Future, Proceeding of IEE, Vol.93, November 2005, pp.1890-1907

[9] Kamphuis, I.; Kok, J.; Wamer, C.; Hommelberg, M.: Massive Coordination of Residential Embedded Electricity Generation and Demand Response Using the PowerMatcher Approach, in the $4^{\text {th }}$ International Conference on Energy EFFICIENCY IN Domestic Appliances and Lighting- EEDAL06, 2007

[10] Rasmus Skovmark, Johan Holkmann Jacobsen: Analysis, Design and Development of a Generic Framework for Power Tradin, M.Sc thesis, available from Technical University of Denmark, 2007

[11] European Commission: New ERA for electricity in Europe: Key Issues, Challenges and Proposed Solutions, EUR 20902, 2003, ISBN 92-894-6262-0

[12] Nord POOL: http://www.nordpool.com/en/

[13] Nordpool Spot: http://www.nordpoolspot.com/

[14] Shi You, Chresten Træholt, Bjarne Poulsen: A Study on Electricity Export Capability of the $\mu$ CHP System with Spot Price, accepted to be published in the Proceedings and presented at the 2009 PES General Meeting, July, 2008 Canada

[15] GAMS: http://www.gams.com/

[16] Jörgen Sjödin, Dag Henning: Calculating the marginal costs of a district-heating utility, Applied Energy 78, 2004, pp.1-18 